\title{
Editorial
}

\section{Encontro Latino-Americano de Escolas e Docentes de Terapia Ocupacional}

\author{
Rosibeth Muñoz Palm¹, Fátima Corrêa Oliver², Rosé Colóm Toldrá ${ }^{3}$
}

Em 10 de outubro de 2011, aconteceu na cidade de São Paulo a sexta edição do Encontro Latino-Americano de Escolas e Docentes de Terapia Ocupacional, ocasião em que docentes e profissionais de terapia ocupacional de sete países latino-americanos e dois países europeus tiveram a oportunidade de apresentar, compartilhar e refletir sobre a formação acadêmica, nos âmbitos da graduação, da pós-graduação estrito senso e da pesquisa em terapia ocupacional.

Participaram da organização do evento a Confederación Latinoamericana de Terapeutas Ocupacionales (CLATO), a Rede Nacional de Ensino de Terapia Ocupacional (RENETO) e o Departamento de Fisioterapia, Fonoaudiologia e Terapia Ocupacional da Faculdade de Medicina da Universidade de São Paulo (USP). A exemplo do que ocorreu nas demais edições, o encontro antecedeu o IX Congresso Latino-americano de Terapia Ocupacional, que neste ano se realizou juntamente com o XII Congresso Brasileiro na cidade de São Paulo, entre 11 e 14 de outubro de 2011.

Iniciando com a contribuição de pesquisadores do campo da educação que refletiram sobre as condições de desenvolvimento do ensino superior em diferentes países da América Latina, e particularmente no Brasil, pretendeu-se possibilitar que os participantes tivessem elementos gerais sobre os desafios colocados para a educação superior na região latino-americana. As reflexões trazidas tornaram evidente a diversidade das realidades nacionais e, o caráter excludente e elitista da educação superior na totalidade da região.

No prosseguimento dos trabalhos, que se deu por meio de mesas redondas e plenária, pode-se perceber que o cenário latinoamericano de formação em terapia ocupacional está centrado no desenvolvimento da graduação e nas estratégias de criação e manutenção de cursos nos diferentes países. Chama a atenção que o ensino de terapia ocupacional, que se desenvolve há cerca de 50 anos, ainda esteja centrado no estabelecimento e consolidação da formação profissional em nível de graduação, conforme também demonstraram as preocupações dos autores nos trabalhos apresentados.

Embora bastante interessantes e inovadoras em suas proposições, são ainda recentes e em pequeno número as experiências de cursos de pós-graduação estrito senso. Este nível de formação, conforme se considerou no evento, é fundamental para viabilizar o desenvolvimento da pesquisa em terapia ocupacional e para possibilitar a constituição de um campo específico de conhecimento em diálogo permanente com a qualificação da assistência. Se, por um lado, é necessário consolidar a graduação na área, esta só se desenvolverá por meio da integração com iniciativas de pesquisa e de extensão de serviços à comunidade, que sejam desafiadoras para o fazer profissional.

O VI Encontro possibilitou, mais uma vez, que docentes e profissionais da região debatessem acerca dos desafios contemporâneos colocados para o ensino e a pesquisa em terapia ocupacional. $\mathrm{O}$ evento contribuiu, também, para que fossem estabelecidos alicerces para a continuidade dos debates e o aprofundamento das trocas internacionais. Para o VII Encontro, a ser realizado na Venezuela, ficaram indicadas as seguintes mudanças: dar ênfase ao trabalho em pequenos grupos e ampliar o período do evento para dois dias assim como viabilizar a presença e participação de estudantes.

O apoio da Universidade de São Paulo, por meio da Pró-reitoria de Cultura e Extensão e da Comissão de Cultura e Extensão da Faculdade de Medicina, bem como da Fundação Faculdade de Medicina, favoreceu a criação de um ambiente acolhedor para os participantes e adequado aos trabalhos propostos. Contar com o apoio de agências de pesquisa brasileiras como a Fundação de Amparo à Pesquisa do Estado de São Paulo (Fapesp) e a Coordenação de Aperfeiçoamento de Pessoal (Capes) tornou possível a participação de pesquisadores e docentes brasileiros e estrangeiros, o registro e documentação visual das apresentações e a organização e disponibilização abrangentes dos Anais do evento, publicados como suplemento especial da Revista de Terapia Ocupacional da USP.

Agradecemos aos apoiadores institucionais, e em especial aos 160 participantes, com os quais, vimos trilhando itinerários para maior reconhecimento e desenvolvimento da terapia ocupacional na região latino-americana, que tem demonstrado vitalidade e possibilidades reais de atuar na consolidação do acesso da população de nossos países aos direitos sociais.

\footnotetext{
1. Membro da Confederación Latinoamericana de Terapeutas Ocupacionales (CLATO) e Profa. Assistente da Universidade Federal do Paraná.

2. Vice-presidente da Rede Nacional de Ensino e Pesquisa em Terapia Ocupacional (2010-2012) e Profa. Dra. do Depto de Fsioterapia, Fonoaudiologia e Terapia Ocupacional da FMUSP.

3. Profa. Dra. do Depto de Fisioterapia, Fonoaudiologia e Terapia Ocupacional da FMUSP.
} 